\title{
Induction of early breeding in red deer (Cervus elaphus) by melatonin
}

\author{
C. L. Adam, C. E. Moir and T. Atkinson \\ Rowett Research Institute, Bucksburn, Aberdeen AB2 9SB, U.K.
}

\begin{abstract}
Summary. Lactating $(\mathrm{N}=12)$ and non-lactating $(\mathrm{N}=6)$ red deer hinds and one stag at pasture were given concentrates $(500 \mathrm{~g} / \mathrm{head})$ containing melatonin $(5 \mathrm{mg} / \mathrm{head})$ daily at $16: 00 \mathrm{~h}$ from 18 June to 16 October. The stag shed the antler velvet and started rutting 5 weeks ahead of untreated stags, and hinds had their first oestrus and ovulation of the breeding season in mid-September, 5 weeks in advance of control lactating $(\mathrm{N}=9)$ and non-lactating $(\mathrm{N}=5)$ hinds. Treated hinds were allowed to mate with the treated stag and control hinds ran in an adjacent paddock with an untreated stag. All hinds became pregnant during the study with all but 2 melatonin-fed hinds (1 lactating, 1 non-lactating) and 1 control hind (lactating) conceiving at the first oestrus.

Melatonin-treated hinds lost slightly more live weight than did controls from June to November, but their suckled calves grew throughout at a rate similar to those of control hinds.
\end{abstract}

\section{Introduction}

The natural breeding season of the red deer (Cervus elaphus) occurs in October and calves are born in June. However, it would be commercially advantageous on many farms for birth dates to be earlier in the year so that the dam produces more milk from spring grass and the calves can reach slaughter weight before winter. The timing of the breeding season is principally controlled, as it is in the sheep, by the seasonal reduction in daylength (Marshall, 1937). Detailed studies on sheep have demonstrated that it is the daily pattern of secretion of the pineal hormone, melatonin, that relays the effect of photoperiod on reproduction (Bittman, Dempsey \& Karsch, 1983). Plasma concentrations of melatonin are elevated during darkness (Arendt, Symons \& Laud, 1981) but can also be raised to nocturnal values during daylight by oral administration of melatonin (Kennaway \& Seamark, 1980). Feeding melatonin in the afternoon therefore signals early sunset (hence short days) and, given daily over a period, has been shown to induce the early onset of the breeding season in ewes (Kennaway, Gilmore \& Seamark, 1982; Arendt, Symons, Laud \& Pryde, 1983) and male white-tailed deer (Bubenik, 1983). Such treatment has also been shown to advance breeding activity in the red deer stag and non-lactating hinds (Adam \& Atkinson, 1984; Nowak, Elmhurst \& Rodway, 1985). However, further investigations are required before assessing the potential for the use of melatonin to bring about earlier calving dates for farmed deer. In the present study we have investigated the fertility of the advanced breeding season and have recorded the effects of feeding melatonin to a group of lactating red deer (because most farm hinds are suckling calves during the period of treatment) as well as non-lactating hinds at pasture (where supplementary feeding is competitive).

\section{Materials and Methods}

Animals and treatments. Two mature stags, each weighing $150 \mathrm{~kg}$, and 32 mature red deer hinds, aged $2-5$ years, were used, including 21 hinds which reared a calf during the study. They grazed 
ryegrass-clover pasture on the Duthie Farm, Aberdeen $\left(57^{\circ} 10^{\prime} \mathrm{N}\right)$ and were grouped in adjacent paddocks for the experimental treatments. Group $M$ comprised one 12-year-old stag, 6 nonpregnant non-lactating hinds and 12 pregnant/lactating hinds (mean calving date \pm s.e.m. 4 June $\pm 3 \cdot 2$ days). Group $C$ comprised one 5-year-old stag, 5 non-pregnant non-lactating hinds and 9 pregnant/lactating hinds (mean calving date 9 June $\pm 3 \cdot 5$ days).

Group $M$ deer were given daily pelleted concentrates $(500 \mathrm{~g} / \mathrm{head})$, containing melatonin ( $5 \mathrm{mg} /$ head adsorbed onto $10 \%$ of the pellets) daily at $16: 00 \mathrm{~h}$ from $18 \mathrm{June} 1984$ until 16 October; thereafter no melatonin was added. Group $\mathrm{C}$ deer were given the concentrates without melatonin throughout. The feeds were given in high troughs $(\sim 0.9 \mathrm{~m})$ out of the reach of young calves.

Live weight measurements of hinds and calves were made every 2 weeks from 28 June and 11 July, respectively, until 19 November, when the stags were removed from the paddocks and after which calves were weaned. Blood samples were taken from the hinds monthly until 23 August, and thereafter twice weekly on Mondays and Thursdays until 19 November, with additional samples taken on 29 November 1984 and 10 January 1985. The samples were collected into heparinized vacutainer tubes by jugular venepuncture at $09: 00-10: 30 \mathrm{~h}$, and the plasma was stored at $-20^{\circ} \mathrm{C}$ until analysed for progesterone.

Hormone assay. Progesterone concentrations in plasma were measured by a modification of the radioimmunoassay method of Henricks, Dickey \& Hill (1971), as described by Adam \& Atkinson (1984). The antiserum (HP/S/53-IIC from Guildhay Antisera, University of Surrey, U.K.) was raised in sheep to progesterone- $11 \alpha$-hemisuccinate-ovalbumen and cross-reactions were $0 \cdot 3 \%$ with 17 -hydroxyprogesterone, $0.8 \%$ with corticosterone, $0.9 \%$ with deoxycorticosterone and negligible for other steroids tested. Intra- and inter-assay coefficients of variation were 9 and $13 \%$ respectively. The sensitivity of the assay was $0 \cdot 2 \mathrm{ng} / \mathrm{ml}$.

\section{Results}

The melatonin-fed stag shed the antler velvet on 22 July, the hardened antlers were removed on 26 July, and he showed precocious development of rutting behaviour. These events occurred 5 weeks earlier than those for the untreated stag in Group $\mathrm{C}$, and another untreated stag not included in this study, which shed the velvet on 27 August and had the antlers removed on 31 August.

Reproductive status in the hinds was determined from progesterone concentrations in their peripheral plasma, as described previously (Adam, Moir \& Atkinson, 1985). Plasma progesterone remained low $(<1 \mathrm{ng} / \mathrm{ml})$ in all hinds during the summer (after calving) and the first ovulation of the breeding season was judged to have occurred on the day which was immediately followed by a sustained increase in plasma progesterone above $1 \mathrm{ng} / \mathrm{ml}$. Conception at a particular ovulation was diagnosed if the progesterone concentration remained consistently high thereafter. The mean date

Table 1. Mean live weights ( \pm s.e.m.) and mean dates of estimated first ovulation of the breeding season ( \pm s.e.m.) for melatonin-fed (M) and control (C) red deer hinds

\begin{tabular}{|c|c|c|c|c|c|c|}
\hline \multirow[b]{2}{*}{ Group } & \multirow[b]{2}{*}{ Status } & \multirow{2}{*}{$\begin{array}{l}\text { No. of } \\
\text { hinds }\end{array}$} & \multicolumn{2}{|c|}{ Mean live weight (kg) } & \multirow{2}{*}{$\begin{array}{l}\text { Mean date of } \\
\text { first ovulation } \\
\text { (days) }\end{array}$} & \multirow{2}{*}{$\begin{array}{l}\text { No. } \text { ㅇ conceiving } \\
\text { at first ovulation }\end{array}$} \\
\hline & & & 28 June & 19 Nov. & & \\
\hline \multirow{2}{*}{ M } & Lactating & 12 & $105( \pm 2 \cdot 4)$ & $95( \pm 1 \cdot 6)$ & $15^{\mathrm{a}}$ Sept. $( \pm 1 \cdot 6)$ & $11 \dagger$ \\
\hline & Non-lactating & 6 & $106( \pm 4 \cdot 4)$ & $101( \pm 3 \cdot 1)$ & $16^{\mathrm{a}}$ Sept. $( \pm 2 \cdot 4)$ & $5 \dagger$ \\
\hline \multirow{2}{*}{ C } & Lactating & 9 & $102( \pm 2 \cdot 8)$ & $96( \pm 2 \cdot 3)$ & $17^{b}$ Oct. $( \pm 2 \cdot 2)$ & $8 \dagger$ \\
\hline & Non-lactating & 5 & $99( \pm 3 \cdot 0)$ & $97( \pm 4 \cdot 2)$ & $21^{\mathrm{b}}$ Oct. $( \pm 1 \cdot 5)$ & 5 \\
\hline
\end{tabular}

a $v s$ b, $P<0.001$ (Student's $t$ test).

$\dagger$ Remaining hinds returned to oestrus and mated. 


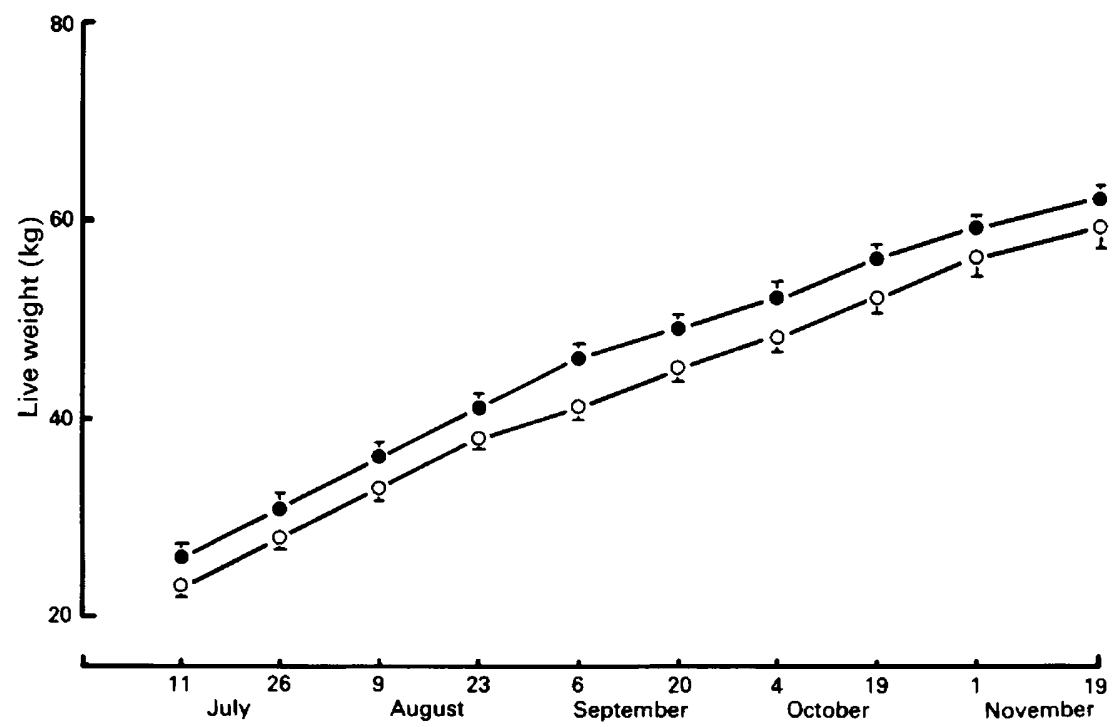

Fig. 1. Mean live weights (with associated s.e.m.) of calves sucking melatonin-fed (M) (O) or control $(\mathrm{C})(\mathrm{O})$ red deer hinds.

of estimated first ovulation for lactating and non-lactating hinds in Group $\mathrm{M}$ was earlier by 32 and 35 days, respectively, than for Group $C$ hinds $(P<0.001)$ (Table 1$)$. All but 2 Group M hinds (1 lactating, 1 non-lactating) and all but 1 hind in Group $C$ (lactating) apparently conceived at their first ovulation. Hinds from both groups that did not conceive at their first oestrus and ovulation subsequently returned to oestrus and mated successfully, and so all deer were pregnant by the end of the period of frequent blood sampling. Progesterone concentrations in the plasma of all hinds remained high on 29 November and 10 January, indicating continued pregnancy.

All hinds showed some live weight loss from 28 June to 19 November (Table 1). Group $M$ hinds lost overall slightly more than did Group $\mathrm{C}$ hinds whether lactating $(10 v s 6 \mathrm{~kg}$ ) or non-lactating ( 5 vs $2 \mathrm{~kg}$ ). However, sucking calves gained on average $36 \mathrm{~kg}$ live weight during the period 11 July to 19 November, showing similar growth curves whether their dams were in Group M or Group C (Fig. 1). Hinds in Group $M$ were seen to be growing their winter coat prematurely at the end of August/beginning of September while Group C hinds still retained the characteristic red summer coat.

\section{Discussion}

Feeding melatonin in the afternoon to groups of hinds at pasture clearly advanced by about 5 weeks the onset of the breeding season in both lactating and non-lactating animals, a similar advance to that seen in individually-fed non-lactating hinds indoors (Adam \& Atkinson, 1984), but in contrast to the results for lactating hinds reported by Nowak et al. (1985). However, unlike previous observations (Adam et al., 1985), non-lactating hinds did not start ovarian activity earlier than lactating hinds within the control or treatment groups.

Although group-feeding was competitive and individual intakes might have varied from day to day, treated deer evidently received sufficient daily melatonin to elicit the early-breeding response seen when animals are fed melatonin individually (Adam \& Atkinson, 1984). It was not practicable to measure the diurnal pattern of plasma melatonin concentrations in deer at pasture, but it was observed in a separate study indoors (C. L. Adam, T. Atkinson \& C. E. Moir, unpublished data) that plasma melatonin was elevated in hinds given $5 \mathrm{mg}$ melatonin daily in their feed at 16:00 h. It 
was probable, therefore, that plasma melatonin was raised in the present trial following ingestion of melatonin. Moreover, as Webster \& Barrell (1985) have demonstrated similar advancement of the breeding season in red deer subjected to artificially shortened daily photoperiod or daily melatonin treatments, it was considered likely that the intake of melatonin in the present trial signalled 'darkness' and hence 'short days' which induced reproductive activity. The mean duration of exposure to melatonin-induced 'short days' before hinds had their first ovulation was 80-90 days.

The stag given a daily allowance of about $5 \mathrm{mg}$ melatonin from June showed an advance in his seasonal sexual development similar to the stag of similar live weight given $10 \mathrm{mg}$ melatonin daily (Adam \& Atkinson, 1984) and to stags implanted with melatonin in May (Lincoln, Fraser \& Fletcher, 1984). Stags apparently require a shorter duration of 'short-day' stimulus than do hinds, and indeed the stag fed melatonin along with hinds in the present study shed the antler velvet after just 35 days and was in full rut at least 2 weeks before the first of the hinds came into oestrus. As the treated and control hinds in adjacent paddocks were exposed to possible pheromonal effects of the early-rutting stag, it is unlikely that these effects alone could account for the advance in onset of ovarian activity shown by melatonin-treated hinds over controls (in agreement with Adam \& Atkinson, 1984). In sheep, however, there is clearly a 'ram effect' which can advance the onset of oestrous cyclicity in some ewes, and the presence of a male can reduce the interval from start of treatment to onset of ovarian activity in ewes given melatonin (Robinson, Aitken, Atkinson \& Fraser, 1985).

Most importantly, the trial clearly demonstrated that the early-induced rut in the stag and oestrus in the hind were entirely normal and fertile. Hinds do not generally show silent heat at the start of their normal breeding season and they usually mate successfully at their first ovulation (Adam et al., 1985). The melatonin-induced early breeding season is apparently no different: most treated hinds conceived at their first ovulation and most calves will therefore be born 5 weeks earlier than usual.

Calves grew at a similar rate throughout whether their dams were melatonin-treated or not (Fig. 1). This was interpreted as an indication that the pattern of lactation in the hind was not affected by exogenous melatonin. The actual calf growth rates could only have been achieved on a diet chiefly of milk at least until September, after which intake of pasture may have made an increasing contribution (C. L. Adam, unpublished data). Hinds on good quality sown pastures lactate well with relatively high daily milk yields for at least 100 days until mid-September (Loudon, Darroch \& Milne, 1984). The total lactation may last 160-280 days (Arman, Kay, Goodall \& Sharman, 1974) but less if the hind becomes pregnant (Krzywinski, Krzywinska, Kisza, Roskosz \& Kruk, 1980). However, in the present study melatonin-treated hinds that became pregnant 9 weeks before removal of their suckled calves did not show a markedly earlier decline in milk production, as judged by the calf growth rates, compared with control hinds that became pregnant 5 weeks later.

Long exposure to melatonin is known to cause growth of winter coat and anorexia in many mammalian species (Lincoln, 1983). The melatonin-treated hinds in the present trial indeed showed premature coat change, and they also tended to lose more live weight than controls, especially if lactacting, from June to November. Most of this loss occurred during September and could well have reflected an early seasonal decline in appetite, occurring at a time when nutritional requirements remained relatively high for hinds suckling calves. However, the live weight of all hinds was high at the start of the study and the weight loss was evidently not sufficiently severe to affect fertility (Hamilton \& Blaxter, 1980) and the establishment of pregnancy.

In conclusion, it is clear that daily melatonin feeding can effectively advance the breeding season in male and female red deer at pasture, whether the hinds are lactating or not, without affecting the live-weight gain of suckled calves, and without adverse effects on fertility. Thus the calving season is effectively advanced and the method could be used to commercial advantage on the farm.

We thank Mr H. MacAlister and the staff of the Duthie Farm for technical assistance. 


\section{References}

Adam, C.L. \& Atkinson, T. (1984) Effect of feeding melatonin to red deer (Cervus elaphus) on the onset of the breeding season. J. Reprod. Fert. 72, 463-466.

Adam, C.L., Moir, C.E. \& Atkinson, T. (1985) Plasma concentrations of progesterone in female red deer (Cervus elaphus) during the breeding season, pregnancy and anoestrus. J. Reprod. Fert. 74, 631-636.

Arendt, J., Symons, A.M. \& Laud, C.A. (1981) Pineal function in the sheep: evidence for a possible mechanism mediating seasonal reproductive activity. Experientia 37, 584-586.

Arendt, J., Symons, A.M., Laud, C.A. \& Pryde, S.J. (1983) Melatonin can induce early onset of the breeding season in ewes. J. Endocr. 97, 395-400.

Arman, P., Kay, R.N.B., Goodall, E.D. \& Sharman, G.A.M. (1974) The composition and yield of milk from captive red deer (Cervus elaphus L.). J. Reprod. Fert. 37, 67-84.

Bittman, E.L., Dempsey, R.J. \& Karsch, F.J. (1983) Pineal melatonin secretion drives the reproductive response to daylength in the ewe. Endocrinology 113, 2276-2283.

Bubenik, G.A. (1983) Shift of seasonal cycle in white-tailed deer by oral administration of melatonin. J. exp. Zool. 225, 155-156.

Hamilton, W.J. \& Blaxter, K.L. (1980) Reproduction in farmed red deer. 1. Hind and stag fertility. J. agric. Sci., Camb. 95, 261-273.

Henricks, D.M., Dickey, J.F. \& Hill, J.R. (1971) Plasma estrogen and progesterone levels in cows prior to and during estrus. Endocrinology 89, 1350-1355.

Kennaway, D.J. \& Seamark, R.F. (1980) Circulating levels of melatonin following its oral administration or subcutaneous injection in sheep and goats. Aust. J. biol. Sci. 33, 349-353.

Kennaway, D.J., Gilmore, T.A. \& Seamark, R.F. (1982) Effect of melatonin feeding on serum prolactin and gonadotropin levels and the onset of seasonal estrous cyclicity in sheep. Endocrinology 110, 1766-1772.
Krzywinski, A., Krzywinska, K., Kisza, J., Roskosz, A. \& Kruk, A. (1980) Milk consumption, lactation and the artificial rearing of red deer. Acta theriol. 25, 341-347.

Lincoln, G.A. (1983) Melatonin as a seasonal time-cue: a commercial story. Nature, Lond. 302, 755.

Lincoln, G.A., Fraser, H.M. \& Fletcher, T.J. (1984) Induction of early rutting in male red deer (Cervus elaphus) by mela tonin and its dependence on LHRH. J. Reprod, Fert. 72, 339-343.

Loudon, A.S.I., Darroch, A.D. \& Milne, J.A. (1984) The lactation performance of red deer on hill and improved species pastures. J. agric. Sci., Camb. 102, 149-158.

Marshall, F.H.A. (1937) On the change over in the oestrous cycle in animals after transference across the equator, with further observations on the incidence of the breeding seasons and the factors controlling periodicity. Proc. $R$. Soc. B 122, 413-428.

Nowak, R., Elmhurst, R.N. \& Rodway, R.G. (1985) A note on the effect of melatonin feeding on the initiation of ovarian activity and on plasma prolactin levels in lactating and non-lactating red deer hinds. Anim. Prod. 40, 515-518.

Robinson, J.J., Aitken, R., Atkinson, T. \& Fraser, C. (1985) The effect of oral administration of melatonin and/or exposure to a vasectomised ram on ovarian activity in ewes. Anim. Prod. 40, 524, Abstr.

Webster, J.R. \& Barrell, G.K. (1985) Advancement of reproductive activity, seasonal reduction in prolactin secretion and seasonal pelage changes in pubertal red deer hinds (Cervus elaphus) subjected to artificially shortened daily photoperiod or daily melatonin treatments. J. Reprod. Fert. 73, 255-260. 